
العدد الثالث عشر / المجلد الأول

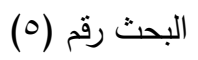

\title{
تكنولوجيا الالواح الخشبية المصنعه من الخامات الصديقة للبيئة وتطبيقاتها فى مجال التصميم
}

\author{
سليم لافى فهيٍ الرشيلى \\ مدرب متخصص (ج) - المعهد الصناعى \\ صباح السالم - الكويت
}




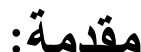

ان التصميم وبخاصة التصميم الداخلى هو احدى انواع التصميمات المختلفة والتى تعمل على خدمة البشرية والانسان فى كافة المجالات المحيطة به وذلك لانها تعمل على ان توفر بيئة ملائمة ومناسبة لكى يستطيع الانسان ان يمارس كافة نشاطاتة المختلفة. والتصميم بما يشمله من تصميمات للفراغات او الاثاث ارتبط ارتباطا وثيقا بتطور الفكر عند الانسان فى كافة المجالات المختلفه وقد ادى نطور هذا الفكر الانسانى الى ظهور ثقنيات رقمية وتكنولوجية حديثة كان لها اثر كبير على تطور الافكار الصميمية ونماذجها. كما ادى هذا التقدم التكنولوجى والرقمى وما صاحبه من ثورة صناعية هائله فى تغييرالكثير من الصفات المختلفة للمواد الخام المستخدمة فى عملية التصميم وذلك لكى تتلائم وتتاسب البيئة المحيطة مع العمل على انتاج وتصنيع خامات بمواصفات جديدة من شأنها ان تقلل من الاثار السلبيه التى كانت تسببها الخامات القديمة عند استخدامها فى عمليات التصميم وهو ما يطلق علية خامات صديقة للبيئه ومن حيث هذه الخامات والتى سوف تقوم بتتاولها خلال هذه الدراسة خاصة الالواح الخشبية وما نم عليها من خلال عمليات التصنيع المختلفة من ادخال وانتاج اخشاب تتميز بالتانة والمرونه الى جانب محافظتها على البيئة المحيطة بها. حيث ان خامة الاخشاب هى اكثر المواد الخام التى يتم استخدامها فى شتى المجالات التصميم.

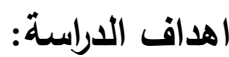

من خلال هذه الدراسة نأمل ان نستطيع تحقيق عدة اهداف منها 1- القيام بدراسة والتعرف على مواصفات وعمليات التصنيع واستخدامات هذه الالواح الخشبية المصنعة للتعرف على افضل السبل للاستفادة العضوي منها. 
ץ-معرفة تأثير استخدام الالواح الخثبية المصنعة من المواد صديقة البيئة على البيئة المحيطة سواء تأثنرات سلبية او ايجابية. r- التعرف على احدث اعمال التصميم الداخلى وتصميم الاثاثات التى تقوم باستخدام الالواح الخشبية المصنعة من خامات صديقة للبيئة.

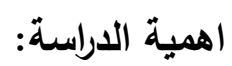

ان اهمية الدراسة ترجع الى انها يمكن ان يكون لها دور ايجابي فى افكار وتتفيذ العمليات

$$
\text { التصميمية وذلك من خلال. }
$$

1- انها تقوم بتوفير معلومات كافية ومفيدة للمصمم حول طرق واساليب التصنيع المختلفة وكيفية استخدام التقنيات الحديثة فى انتاج اخثاب من مواد خام صديقة للبيئة. ץ-التعرف على الدور الهام الذى تقوم به الالات والماكينات الحديثة والمرتبطة بالتكنولوجيا

$$
\text { الرقمية فى انتاج وتصنيع وتشكيل هذه الالواح الخشبية. }
$$

ז- العمل على تشجيع المصممين المعماربين على التوسع وزيادة استخدام الالواح الخثبية المصنعة من مواد خام صديقة للبيئة فى تصميماتهم سواء الداخليه والتى تتمنل فى شخل الفراغات الداخلية بما يناسب الفرد او من حيث تصنيع الاثاث باستخدام هذه الالواح لما لها من صفات وخواص جيدة وتأثنرات نفسية ايجابية على الفرد عند استخدامها. مصطات الاراسة:

ا- المواد الخام: (Raw materials)

وهى عبارة عن مادة او منتج طبيعى موجود فى البيئة المحيطة ويمكن القيام

$$
\text { بأستخدامه فى تصنيع او انتاج شئ جديد.(1) }
$$




\section{Y الالواح الخشبية المصنعة: Manufactured wood panels}

وهى عبارة عن الواح خشبية يتم تصنيعها فى مصانع خاصة وتتتج من الياف او

خامات خضراء أو مخلفات نشاره الاخثاب والمخلفات الزراعية يعاد تدويدها من جديد بحيث

تكنسب خواص جديدة تختلف عن الاخشاب الطبيعية.(r)

الاطار النظرى : (1)

ان الاخثاب من اهم المواد الخام التى قام الانسان بأستخدامها على مر التاريخ وذلك

من خلال استخدامها فى مجالات ووظائف متعددة سواء كان ذلك من خلال اعمال البناء والمعمار او خلال تصنع الاثاث بشتى صورة واشكالة المختلفة.

وعلى الرغم من ان الاخشاب لم تكن تستخدم من قبل الا فى انتاج مصادر للطاقة او الحرارة او اعمال البناء البدائية الا انه من خلال التقام التكنولوجى والتقنيات الحديثة التى تقدمت وازدهرت فى الاوانة الاخيرة وما صاحبها من انتاج ماكينات والالات حديثه تعتمنى عملها على الحاسب الالى وبرامج التكنولوجيا الحديثة والتى استطاعت الانسان من خلال استخدام هذه الالات فى القيام تصنيع انواع واشكال جديدة من الالواح الخشبية مصنعة من خامات ومخلفات صديقة للبيئة وهى التى بطلق عليها الاخشاب المصنعه ـ والتى انتشر استخدامها فى مجالات متعددة وخاصة فى مجال التصميم وانتاج الاثاث وشغل الفراغات الداخلية لميانى لـى لهى كما اصبحت تستخدم فى تجليد وتكسية الحوائط المختلفة لما لها من صفات وخواص تتسم

بالجودة المتانة الى جانب تمتعها بالثكل الجمالى والذوق الرفيع.(() والالواح الخثبية المصنعة من مواد خام صديقة للبيئة يتم انتاجها من مخلفات مثل مخلفات

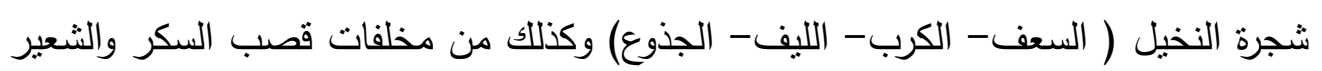
وقنثور الارز والحنطه وغيرها من المخلفات الزراعية. 
انواع الاخشاب المصنعة:

Plywood أولا : الواح الخشب (الابلاكاج)

وسمك هذه الالواح يتراوح بين 1,0- r ملم وتعتبر الالواح الخشيية المصنعة من تلات طبقات من رقائق الخشب هى افضل انواع الالواح الخشبية المعاكسة وهذا النوع من الاخشاب المصنعة يتم انتاجه وتصنيعة بواسطة لصق الرقائق الخاصة بالقشرة الخشبية فوق بعضها البعض على ان يكون اتجاه الالياف متعاكس مع بعض البعض من اجل ذلك اطلق عليه الالواح المعاكس حيث ان هذه الطريقة الصق والتصنيع تصل على زيادة متانة وقوة الالواح الخثبية ومقاومتها للرطوبة كما انها تمتاز بجمال المظهر الخارجى للالواح الخشبية.

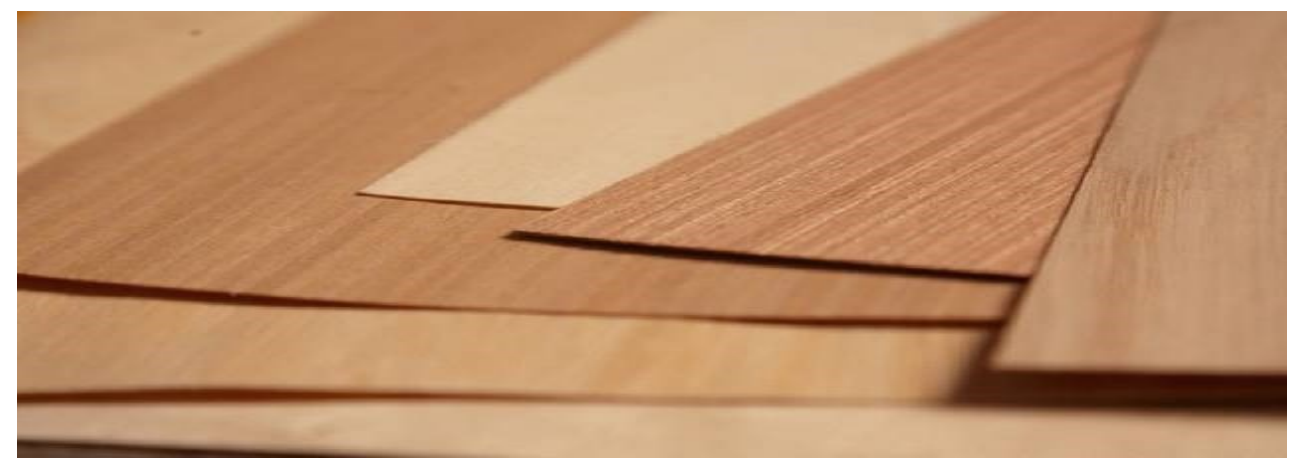

1- Fruehwald, A., Thoemen, H. (2008)' The rise of wood based panels. Presentation during the 3rd International Wood Academy, University of Hamburg طرق واساليب تصنيع الالواح الخشبية المعاكس(الابلاكاج) 1- 2 - عن طريقة الكبس الساخن

حيث تستخدم مكابس هيدرولويكيه وتكون درجه حرارتها بين TN الى IV I درجة مئوية

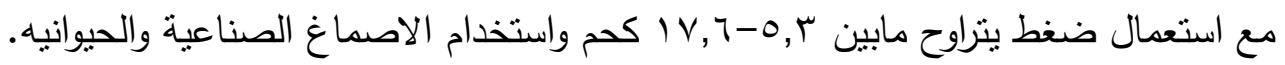
r - عن طريق الكبس البارد 
وذللك عن طريق كبس الالواح بواسطة مكابس هيدروليكية فى درجة الحرارة العادية على ان نقوم بأستخدام لاصق واصماغ صناعية او حيوانية والتى تجف وتتصلب فى درجة الحرارة

$$
\begin{aligned}
& \text { العادية مثل صمغ (اليوريا فورما لدهايد).((1) } \\
& \text { خصائص الواح الخشب (الابلاكاج): }
\end{aligned}
$$

انه مقاومة للالتواء والتثقق كما انه يتمتع بثبات الابعاد عند تعرضه للرطوبه كما يتمتع بجمال الاشكال والالوان.

$$
\text { استخدامات الواح الخشب المصنع (الابلاكاج) }
$$

يستخدم فى صناعة الاثاث الفاخر والمبانى الخثبية كما انه يستخدم فى اغراض التجميل وعمل الاسقف وتغطية الارضيات والجدران والحوائط وفى اوجه الابواب الخشبية واعمال الديكور المختلفة كما يتمتع به من قوة وتحمل ومتانه ومرونه فى الاستخدام.(؟) ثانيا : ألواح الخشب المضغوط وهى الواح خشبية مصنعة من مخلفات المصانع التى نقوم بتحضير الخشب الخام أو الطبيعى حيث انه يصنع من نشارة الخشب بمختلف ابعادها واحجامها وانواعها عن طريق تجفيفها جيدا للقضاء على الرطوبة بداخلها ثم تخلط بالمواد اللاصقة المناسبة لها وتكبس بالككابس الهيدروليكية على شكل الواح متعددة السماكات والأطوال .الى جانب استخدام المخلفات الاخرى مثل المخلفات الزراعية كأحطاب القطن و مصاصة القصب وسيقان نبات الارز وسيقان نبات الكتان الى جانب مخلفات مصانع عصر الزيتون ويمكن استخدام الخشب المضغوط مع طبقة اخرى من خشب البلوط لكى يعطى المتانة والقوه والثكل الجمالى عند استخدامة فى تصنيه الاثاثات الخثبية ححيث انه من حيث الثكل فهو لا يتمتع بالاشكال الجمالية لذا يفضل دهانة بألوان مختلفة او تكسيتة بطبقة اخرى من القشرة

(الخشبية لكى تضفى عليه الشكل الجمالى.(') 


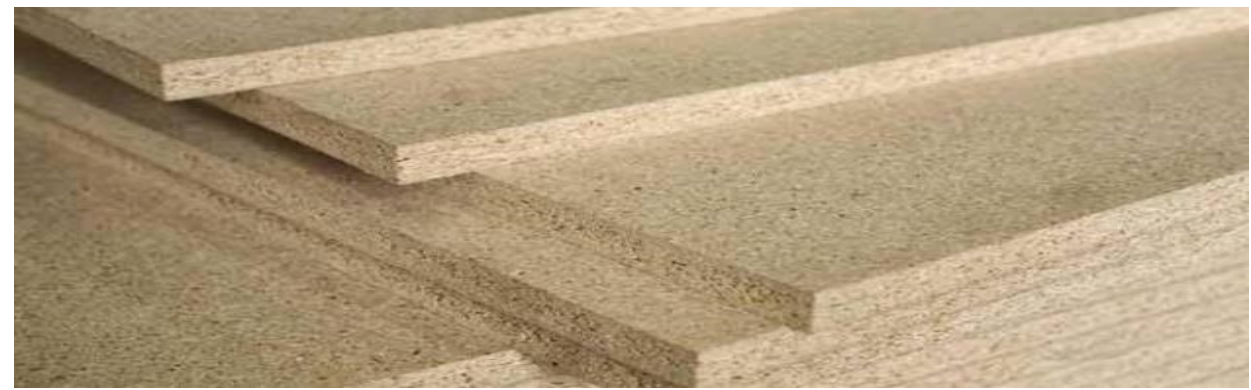

ثالثا : الواح الخثب الصناعى الحبيبي (الاوكال)

وهى الواح من الخشب المضغوط ويصنع من نشارة الخشب او من مصاص قصب

السكر وكذلك يمكن تصنيعة من سيفان نبات الارز وقتشر الفول السودانى او سيفان نبات الكتان وينم تصنيعها عن طريق لصقها بواسطة مواد كيميائية ثم تكبس عن طريق المكابس الهيدروليكية تحت ضغط معين طبقا للاغراض المطلوب استخدامها فيه. ولقد ظهرت هذه الصناعة لألواح الخشب الحبيبى فى نهاية الخمسينات ونتيجة التطور التكنولوجى والرقمى الذى حدث خلال الأونه الأخيرة وما نتج عنه من استخدامات لألات وماكينات وطرق حديثة ومتعددة ومنطورة فى عمليات الصناعه ككل وصناعة الأخشاب بصفة خاصة أدى ذلك الى تطوير صناعة الواح الخشب الحبييى أو الأوكال حيث انه يعتبر البديل المناسب للأخشاب الطبيعية حتى انه تفوق عليها فى الأستخدام وذلك نظرا الى ندرة الغابات التى يتم اسنخراج الاخثاب الطبيعية منها الى جانب التكلفة الاقتصادية القلبلة بالمقارنه الى تكلفة استخدام الواح الاخثاب الطبيعية. وقد آدى ذلك الى زياده الطلب عليها وكثرة استخدامها وخاصة فى التصميمات الداخلية للمبانى الى جانب تصنيع الأثاثات المختلفة 


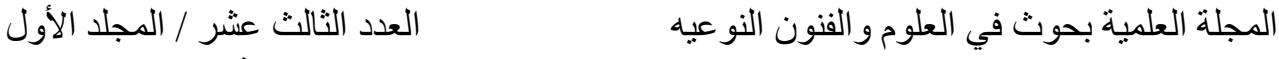

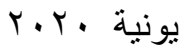

وترجع اهية الخشب الحبيبى الى انه من الألواح الصديقة للبيئة حيث انه يقوم فى تصنيعة على المخلفات الزراعية ومخلفات المصانع مما يتيح الاستفادة من هذة المخلفات واعادة تدويرها بتكلفة اقتصادية قليلة الى الواح خشبية نستقبد منها فى مجالات متعددة.(1)

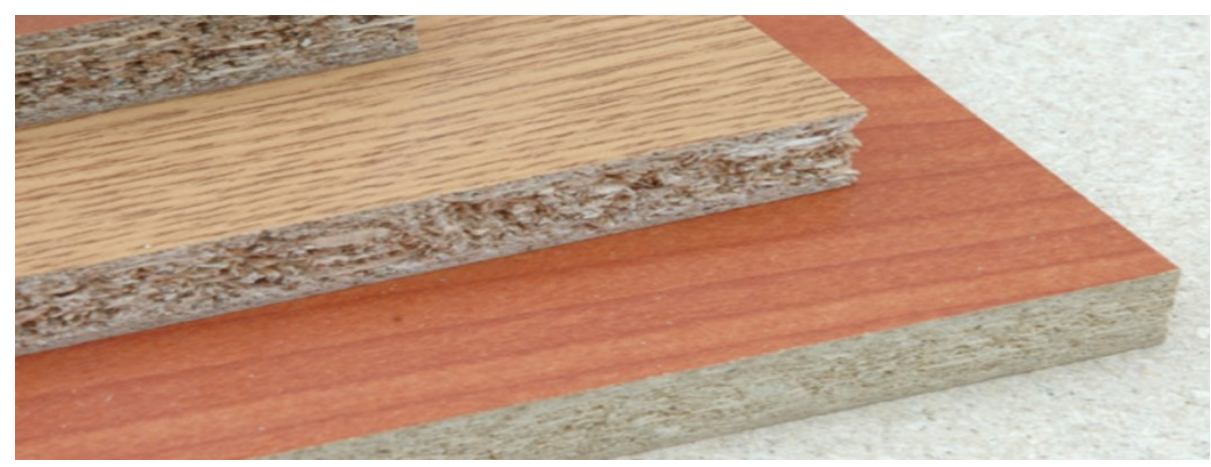

1- NPA. 1993. Particleboard, ANSI A208.1-1993. Gaithersburg, MD: National Particleboard Association.

$$
\text { (استخدامات الواح الخشب (الاوكال) }
$$

تستخدم الواح الخشب الحبيبي (الاوكال) فى تجليد الحوائط والجدران بغرض عزل

الصوت او الحرارة كما انها تستخدم فى تصنيع العديد من الاثاثات واعمال النجارة المختلفة. ويعتبر هذا النوع من الالواح الخشبية المصنعة من مخلفات ومواد صديقة للبيئة البديل الامثل للاخشاب الطبيعية ولكنها تمتاز عن الاخشاب الطبيعية بأنخفاض تكلفتها حيث ان هذا النوع من الاخشاب يعتمد فى المقام الاول عند تصنيعه على المخلفات الزراعية مما يجعله منخفض التكلفة الاقتصادية فى حالة استخدامة فى المبانى والتصميمات وصناعة الاثاث.(() 


$$
\begin{aligned}
& \text { العدد الثالث عشر / المجلد الأول }
\end{aligned}
$$

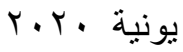

إيعا : الواح الخشب الحبيبى الأسمنتية : Cement bonded particleboard نتيجة التقام التكنولوجى وازدباد الاختباج الى انواع جديدة من الاخثاب يستطيع من خلالها المصمم المعمارى والداخلى تلبية احتياجاته فى تتفيذ العملية التصميمية ظهرت انواع جديداة من الالواح الخشبية التى تم دمجها مع الاسمنت مما اضاف الى خصائص الاخثاب من خفة وزن وليونه خصائص اخرى يتمتع بها الاسمن من القوة والمتانة والصلابة فظهرت ما اطلق عليه الواح الاخشاب الاسمنتية ويتم تصنيعها عن طريق خلط حبيبات الخشب الصلبة الناتجة من مخلفات المصانع والمخلفات الزراعية بعد فرمها بما يمنل من ه ب الى •r\%والباقى مادة اسمنتية أو جبس وتنتخدم هذة الالواح كبديل للجمسم بورد فى أعمال الزخرفة للتصميمات الداخلية وهذة الالواح تمتاز بمقاومتها للرطوبة والحرارة والعوامل والظروف المناخية كما يمتاز بمقاومته للحشرات والحرائق وهى الواح عازلة للصوت.(()

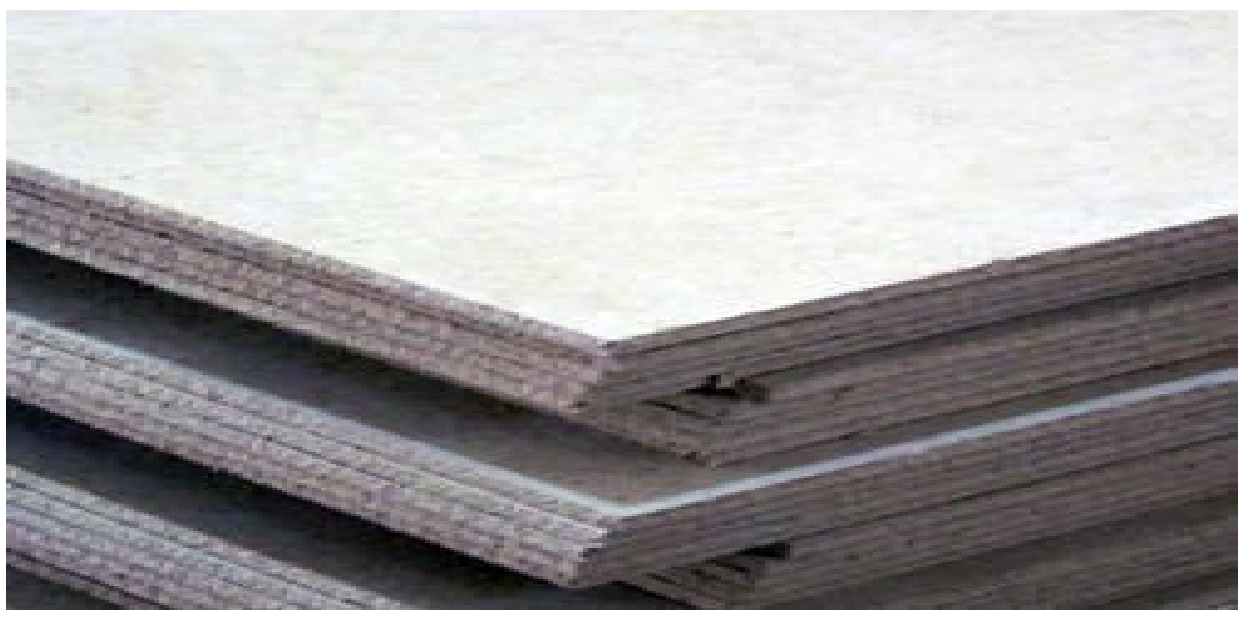

1-. BS EN 634-2:2007 Cement-bonded particleboards. Specifications. Requirements for OPC .bonded particleboards for use in dry, humid and external conditions, BSI 


\section{خامسا : الواح الخشب الليفى :}

وهو نوع من الالواح الخشبية التى تعتمد فى تصنيعها على المخلفات الزراعية ومخلفات الاخشاب الطبيعية وذلك عن طريق فرمها وخلطها بالمواد اللاصقة وتحويلها الى عجينة خشنة حيث تصبح فى شكلها الخام عبارة عن كتل خشبية صغيرة الحجم ومن خصائص هذه الالواح انها تختلف طبقا للمواد الخام والمخلفات الزراعية المصنوعة منها حيث انها تصنع من جذوع ومخلفات الأشجار الغير قابلة للنشر كما ان هذه الالواح يتم تصنيعها ايضا من مخلفات تقليم الأشجار ومن أهم المخلفات التى تستخدم فى تصنيع هذه

$$
\begin{aligned}
& \text { الالواح ( الصنوبر - التتوب - الزان - السنديان - الحور - البتولا). } \\
& \text { أنواع الالواح الليفية : }
\end{aligned}
$$

High density fiber board (HDF) الألواح الليفية ذات الكثافة العالية وهى الواح من الخشب الليفى الذى تترواح كثافتة من ^.. الى ؟. ا حيث ان هذة الكثافة العالية نساعد فى زيادة قوتها ومتانتها وصلابة الاسطح الى جانب مقاومتها العالية للرطوبة

$$
\text { والحرارة }
$$

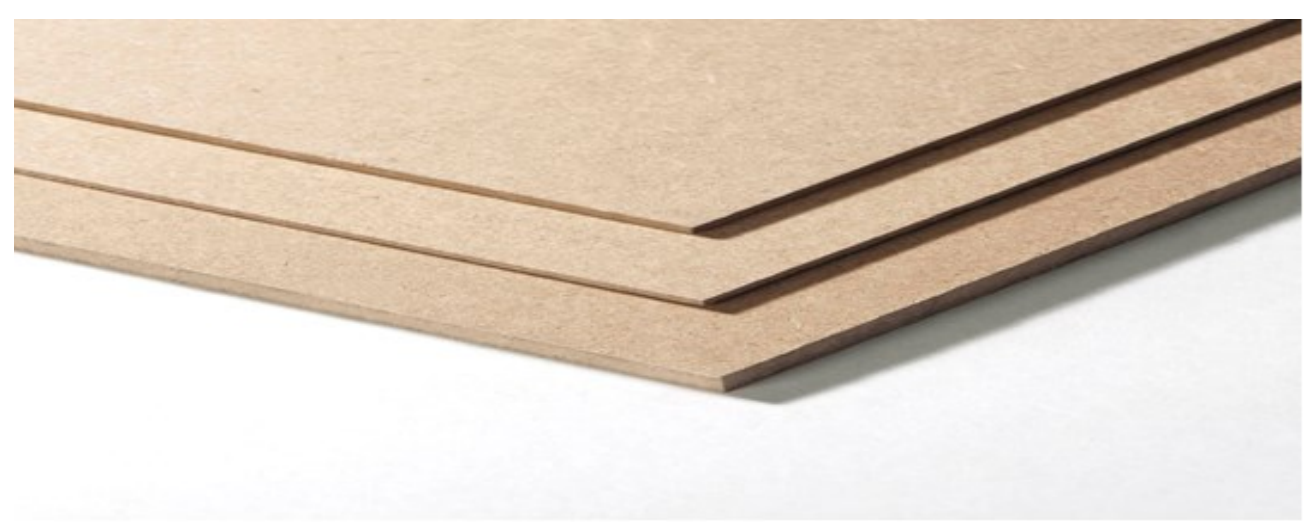


ويكثر استخدامها خاصة فى الارضيات نظرا لقدرتها الكبيرة على تحمل الصدمات والضغط عليها حيث انه يتم تصنيعها بطريقة الضغط.(1) Yedium Density Fiberboard(MDF) بألواح الخشبية ذات الكثافة المتوسطة وهى الواح من الخشب الليفى المضغوط وتكون كثافتها متوسطة ويطلق عليها (MDF) الواح ويتم تصنيع هذه الالواح عن طريق اعادة تدوير المخلفات من الاخشاب الطبيعية والكرتون المضغوط والمخلفات الزراعية الاخرى من الاشجار المختلفة ويتم تشكيلها عن تعريض هذه المخلفات بعد فرمها بحيث تتسم بالخشونه مع خلطها بالمواد اللاصقة المناسبة منل غراء الكارباميد ثم تتعرض الى درجات عالية من الحرارة والضغط الثديد .

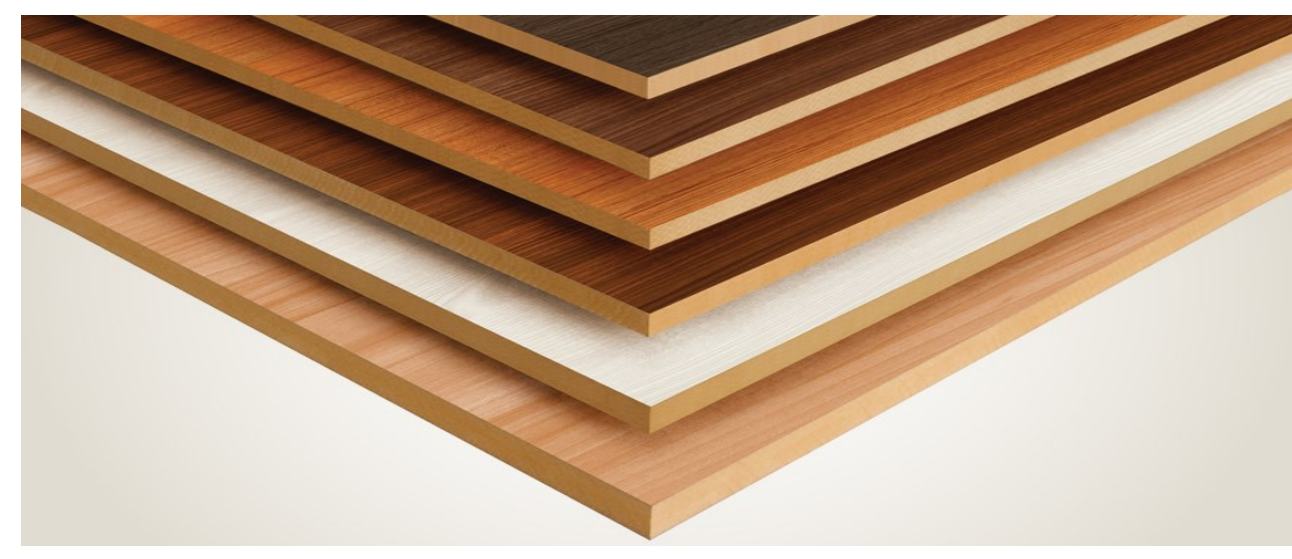

1- BS EN 622-‘(:2009)’ Fibreboards. Specifications. Requirements for dry process boards. وتمتز هذه الالواح بقدتها على مقاومة الرطوبة ويمكن وضع قثرة الخشب عليها لأعطائها الثكل الجمالى وتستخدم هذة الالواح فى تصنيع الاثاثات المختلفة وفى صناعة المطابخ والابواب واسطح الطاولات كما نستخدم فى التصميمات الداخلية المختلفة. (1) 


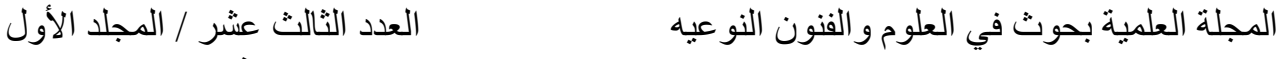

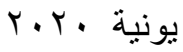

\section{Low density fiber board (LDF) ب الألواح الليفية ذات الكثافة المنخفضة}

وهذه الالواح تتم تصنيعها بالطريقة المائية حيث انها لا تتعرض للتغط نهائيا وكثافتها تكون أقل من ء ... كما انها مكن استخدام هذة الالواح فى عمليات العزل على ان يتم رفع كثافتها لكى تترواح ما بين r ... الى 10 . . وتتميز هذة الالواح بالسطح الناعم الأملس

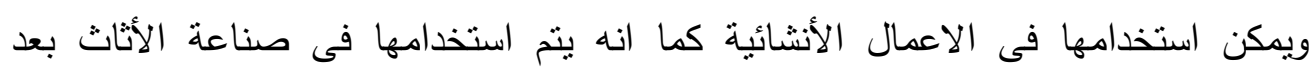

$$
\text { تغطيتها بقشرة خشبية أو بألواح الفورمايكا.(r) }
$$

\section{عecorative masonite fiber board ألواح المازونيت المزخرف}

وهى نوع من الألواح الليفية والتى يتم انتاجها فى اشكال متعددة منها المربع وشكل النجمه أو علامة الزائد ويتم ادخال الثكل الجمالى عليها بأستخدام مكابس هيدروليكية حيث انها يكثر استخدامها فى اعمال الزخرفة والتجميل للتصميم الداخلى وزخرفة واعطاء اشكال جمالية

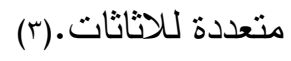

1- NP'(. 1994). Medium density fiberboard (MDF), ANSI A208.2-1994. Gaithersburg, MD: National Particleboard Association.

2- Maloney, T.M. 1993. Modern particleboard and dry-process fiberboard manufacturing. San Francisco, CA: Miller Freeman Publications.

r- مجدي راغب الخالدي،(r (r)، النجارة والديكور(العلوم الصناعية والتدريب العملي)، المستوى، الثالث، وزارة التربيه والتعليم،الاردن

$$
\text { سابعا : الواح الخشب اللاتية (القلب) }
$$

وهى الواح من الخشب الذى يتم صناعته بمخلفات نشارة الاخشاب الناتجة من المصانع المختلفة الى جانب المخلفات الزراعية حيث يتم طحنها جميعا ثم خلطها بالمواد اللاصقة المناسبه ويتم حشوها بين طبقتين خارجيتين من قشرة الخشب ولذلك اطلق عليها ايضا الواح الخشب الساندويتش أو القلب وهذه الالواح 


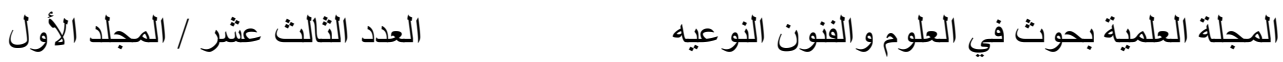

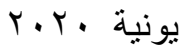

لها العديد من الخواص والصفات منها مقاومتها للرطوبة ومقاومتها للانكماش والالتواءات الى جانب تكلفتها الاقتصادية القليلة بالمقارنه بالانواع الاخرى من الاخشاب المصنعة .(1)

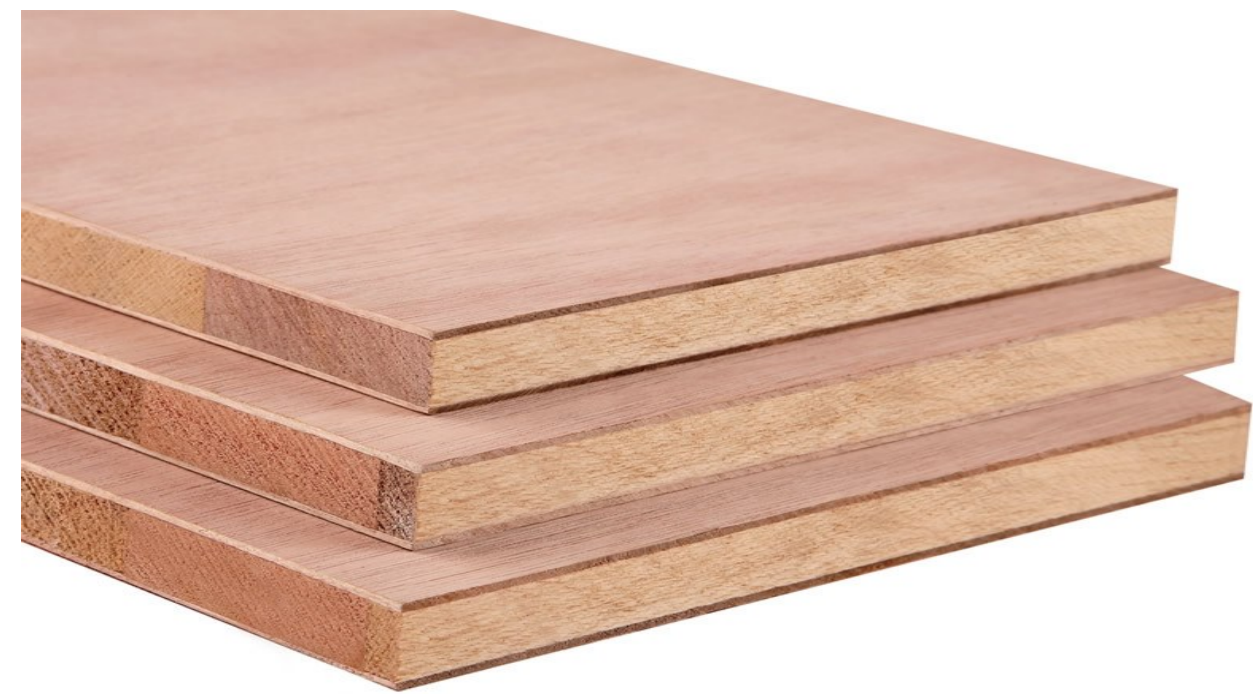

1-(Davidová, Marie'(2016)' Wood as a primary medium to architectural performance : a case study in performance oriented architecture approached throught systems oriented design.

\section{استخدامات الواح الخشب القلب}

تستخدم هذة الالواح على نطاق واسع فى صناعة الاثاثات لما تمتز بة من سهولة فى عمليه تجميعها أو ثقبها أو ربطها بالمسامبر كما ان هناك انواع اخرى ينم تكسيتها بالفورمايكا أو قثرة الخشب ثم طلائها بدهان لامع لكى يجعلها اكثر رونق وجمال عند استخدامها فى الاثاثات المختلفة . وهناك انواع اخرى من الخشب القلب التى ينم صناعتها بواسطه الواح الخشب المعاكس وتكون حشوتها من مخلفات ونشارة اشجار التتوب أو الصنوبر لما تتمنز به هذة (HDF) الاثجار من صلابة وقوة ومثانة حيث انه يتم استخدام هذه الالواح فى صناعة انواع من الاثاثات التى تتطلب ان تكون على قدر عالى من القوة والمتانة 
الى جانب انه يكثر استخدامها فى صناعة المطابخ والارفف والادراج واسطح الطاولات كما

(1). يمكن استخدامها فى تجهيز الارضيات الخثبية (Wood polymer composite) امنا : الواح الخشب البلاستيكى وتصنع هذة الالواح عن طريق خلط مخلفات الاشجار مثل شجر النخيل ومخلفات مصانع الاخشاب مع مادة (البولى اثثلين) او (البولى أستر) ويتم اضافة مواد كميائية للربط بين المادتين ومن اهم مميزات الخشب البلاسنيكى انه مقاوم للحريق والتعفن ويقاوم الحرارة والرطوبة كما يمتاز بطول فترة العمر الافتراضي له ومن ميزاته الجماليه انه يعطى نفس الشكل الجمالى للاخشاب الطبيعية.

1- https://theconstructor.org. كما انه يستخدم فى المناطق شديدة الرطوبة ومن استخدامات الخشب البلاستيكى الاثاث والابواب وهناك عدة انواع للخشب البلاستيك نذكر منها.(()

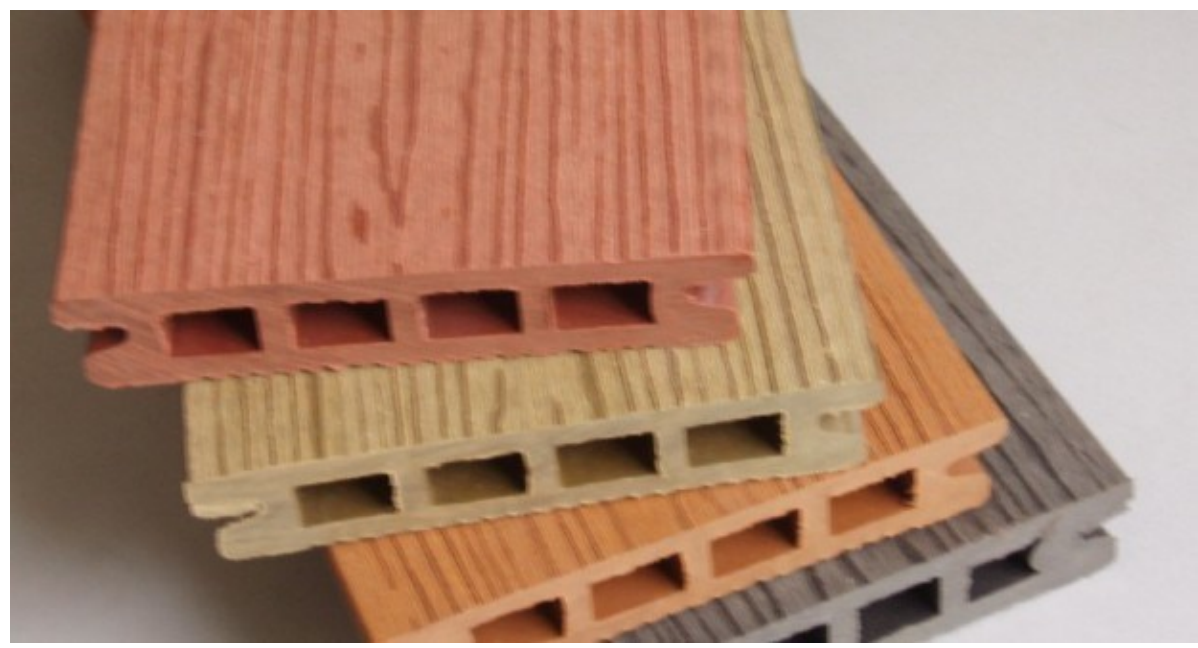


ا - الواح الخشب البلاستيك المركب:

وهى من الالواح التى تستخدم فى الاسطح والواجهات الخاصة سواء فى المنشأت

التجارية او المنازل حيث انها تتوفر بألوان واشكال متعددة.

$1-$ https://europlywood.com/

r - أرضيات الخشب البلاستيك المركب:

وهو نوع جديد من الالواح الخثبية التى تستخدم فى الارضيات حيث انه يثبه الى حد

كبير ارضيات الباركية المصنعة من حيث الاانه يختلف عنه فى انه يصنع من مواد مركبة كما انها بمتاز عنه بأنه من الاخشاب الصديقة للبيئة.

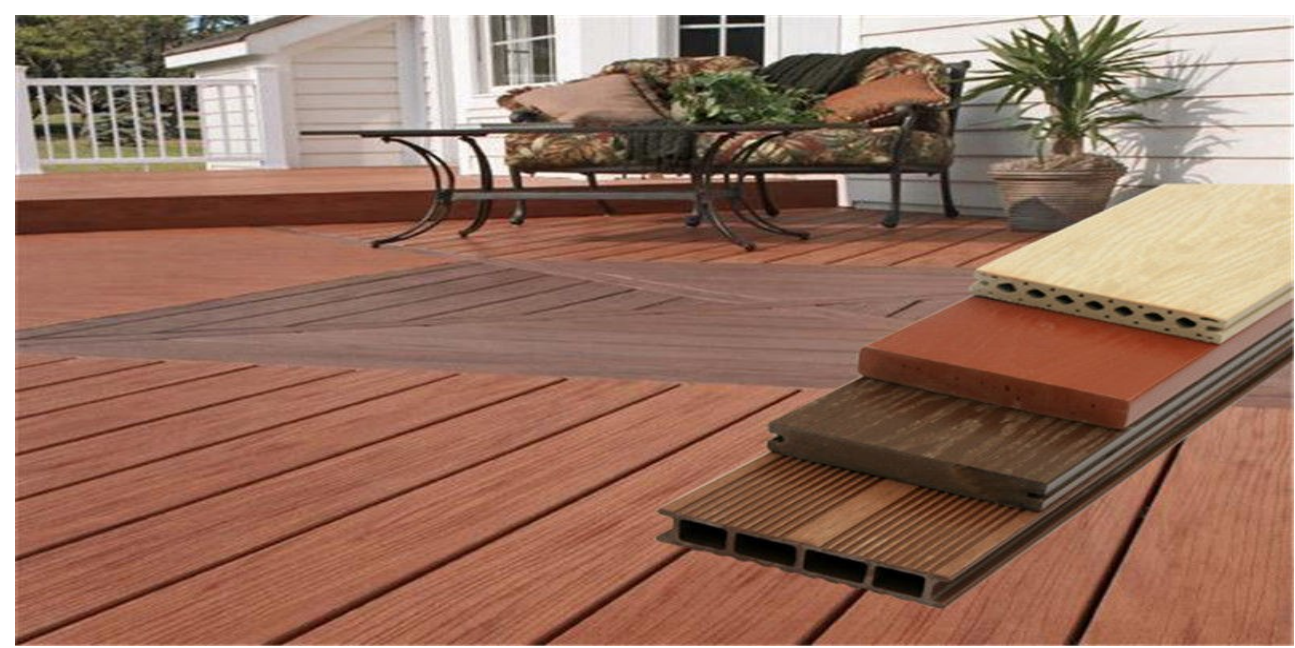

ويمتاز هذا النوع ايضاً من الالواح بمقاومته للامطار لذا يمكن استخدامه فى الواجهات الخارجية وحمامات السباحه كما انه لا يتاثر بالحرارة او البرودة فيصلح فى الاسطح الخارجية

(1). (1) - (1)

1- http://singcore.com/education/faq. 


\section{تطبيقات على استخدام الالواح الخشبية المصنعة فى التصميمات:}

\section{الأرضيات من الالواح الخشبية المصنعة :}

لقد تطورت صناعة الارضيات الخثبية من الواح الخشب المصنع نتيجة تأثير النطور التكنولوجى على مجال التصميمات المعمارية والداخلية للمبانى فاصبح هناك تتافس بين الثركات المختلفة فى انتاج العديد من الالواح الخشبية المصنعه والتى تشتخدم فى الارضيات ولكل شركه اصبح هناك اختلاف فى مواصفات وخصائص هذة الالواح طبقا لنوع الفراغ المستهدف أو نوع الارضيات المطلوبة ومنها :

\section{أ - ارضيات الباركية من الاخثاب المصنعة:}

وهذا التوع من الارضيات يتم انتاجة عن طريق طبقات متعددة ورفيعة من الالواح المضغوطه والنى نم تصنيعها من الالياف الخشبية المعاد تدويرها ثم تكسى بقشرة من الخشب الطبيعى يتميز هذا النوع من الارضيات بالقوة والمتانة والقدرة على تحمل الضغط والتغيرات المناخية حيث ان درجة مقاومتة اعلى من مقاومة الخشب الطبيعى ويتم تركيب هذة الالواح او (المربعات عن طريق اللصق او التثبيت بالمسامير . (1) ب - ارضيات البامبو

وهى الواح عبارة عن جدائل وشرائح من البامبو او الخيزران المضغوط والتى ينم لضقها جنبا الى جنب بحيث تصبح هذه الالواح صلبة وتشبة الى حد كبير الواح الخشب الطبيعة.

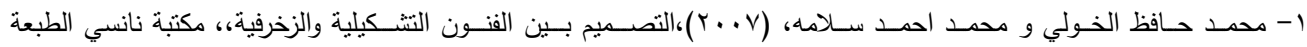


من اهم مميزات ارضيات البامبو القوة والمتانة حيث انها تعتبر اقوى من ارضيات الخشب الطبيعى وتمتاز بمقاومتها للظروف المناخية المختلفة والمباة والرطوبة وهة تتاسب جميع الفراغات الداخلية ويتوفر منها العديد من الالوان والمقاسات المختلفة وتعتبر من افضل الالواح الخثبية المصنعة الصديقة للبيئة.(1) الأثاثات والالواح الخشبية المصنعة: ان الأخشاب هى اكثر المواد التى يتم استخدامها فى تصنيع الاثاثات على اختلاف انواعها واحجامها واثكالها واستخداماتها ونتيجه ارتفاع الاسعار بالنسبة لالواح الاخشاب الطبيعية اصبح هناك اعتماد كبير فى تصنيع كافة انواع الاثاث على الأخشاب المصنعة وخاصة الصديقة للبيئة نظرا لقلة التكلفة الاقتصادية لها بالمقارنة بالاخشاب الطبيعية الى جانب ان التقدم التكنولوجى اتاح لهذة الالواح الخشبية المصنعة العديد من الصفات والخصائص المميزة والغير متوفرة فى الاخشاب الطبيعية مثل مقاومة الحشرات والظروف المناخية ومقاومة الحرائق وعزل الاصوات وعيرها من الصفات التى شجعت على استخدام هذة الالواح الخشبية (r). المصنعة فى شتى مجالات تصنيع الاثاثات التصميم الاخلى والفراعات : اصبح استخدام الالواح الخشبية المصنعة من مواد صديقة للبيئة من الضروريات فى أعمال التصميمات الداخلية ويتمثل ذلك فى الأبواب والثبابيك الى جانب الانشاءات المعمارية والتصميمية الداخلية.

1- http://www.woodplasticcompositepanel.com. r- محمد السيد سيد احمد ،(11 • ب)، تكنولوجيا التصميم الداخلى والأثاث ، دار الزعيم للنشر والتنوزيع ، القاهرة. 
كما اصبحت تستخدم ليس فقط فى اعمال تصميم المنازل ولكن فى التصميمات الداخلية للسفن والطائرات والقطارات وغيرها. الى جانب ذلك ساعدت الأخشاب الصناعية المصمم الداخلى على ابتكار افكار جمالية وزخرفية جديدة بستطيع من خلالها وعن طريق استخدام هذه الالواح بما تتمتع به من صفات وخصائص متعددة ان يقوم المصمم الداخلى بتتفيذ افكار تصميمية من شأنها اعطاء الثكل الجمالى والزخرفى سواء فى الفراغات الداخلية من تكسية للجدران أو حتى فى زخرفة وتجميل الاثاثات المختلفة عن طريق انتاج الحلايا والكرانيش. ( )

\section{تطبيقات على استخدام الواح الابلاكاج فى التصميم :}

يمكن استخدام الواح الابلاكاج فى اضفاء الثكل الجمالى على الحوائط والجدران عن طريق هـ

تكسيه هذة الحوائط والجدران بألواح الابلاكاج ودهانها بالألوان المختلفة كما انه يمكن استخدامها فى تكسية الواح الاخشاب الآخرى التى تستخدم فى صناعة الاثاثات لتعطى الثكل الجمالى الى جانب التصميم الانسيابى الذى يتتاسق مع التصميمات الداخلية للفراغات .

$$
\text { (1)(1) (شكل رقم (1) }
$$




$$
\begin{aligned}
& \text { المجلة العلمية بحوث في العلوم و الفنون النوعيه العدد الثالث عشر / المجلد الأول }
\end{aligned}
$$

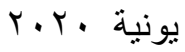

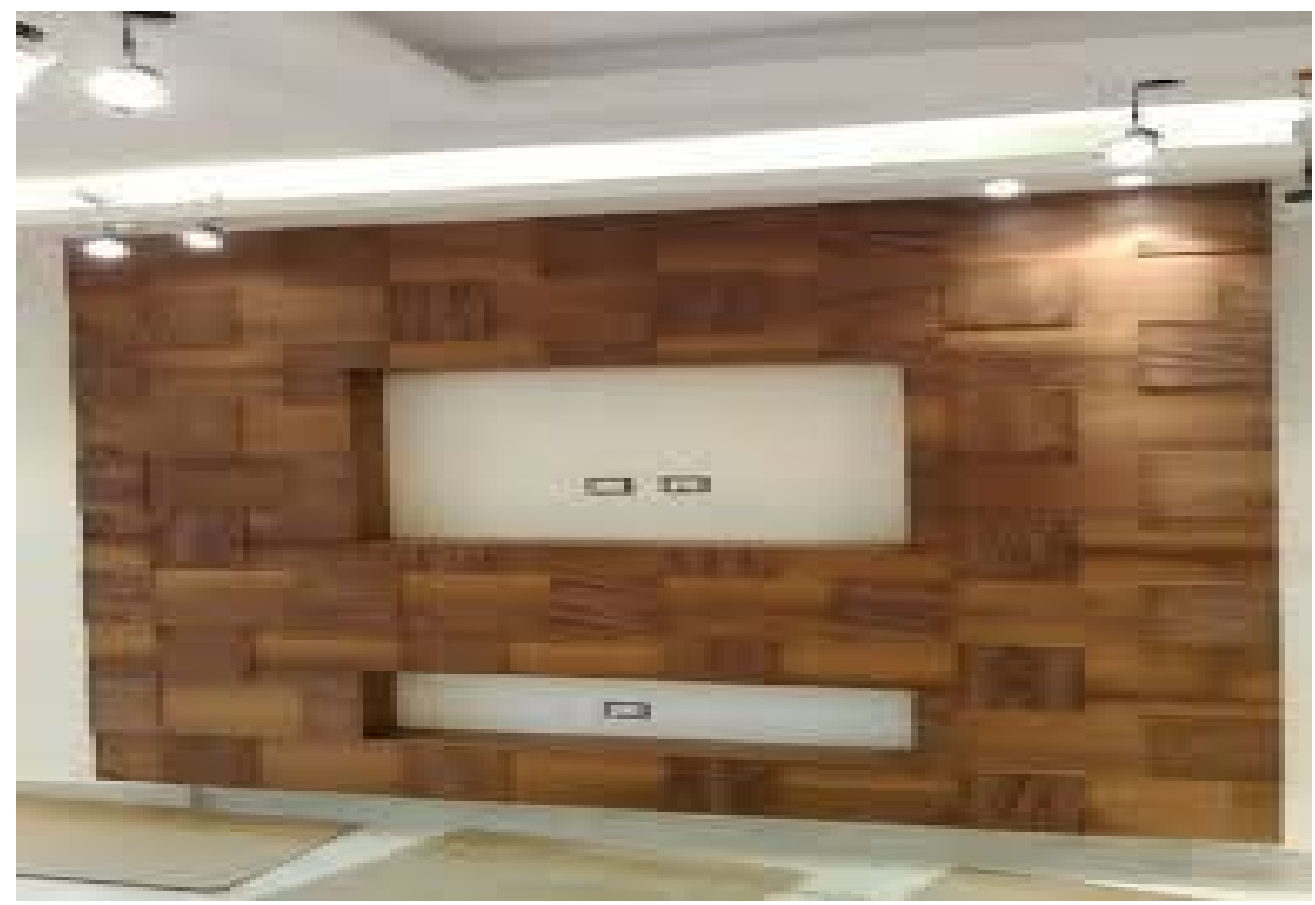

استخام الواح الابلاكاج فى تكسيه الحوائط (شكل رقم ')

1- http://worldarab.mam9.com

فى التصميم MDF تطبيقات على استخدام الواح

استخدام الواح الخشب الليفى ذات الثافة المتوسطه فى تكسية جدران وحوائط المنازل حيث انه يتميز بالقوة والمتانة الى جانب عزل الاصوات لذا فهو مناسب لأستخدامة فى التصميمات الداخلية للفراغات الداخلية.(شكل رقم r ) كما يستخدم فى صناعة الأبواب المختلفة .

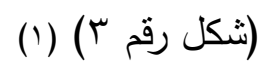




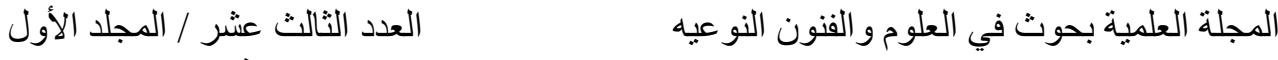

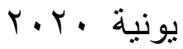

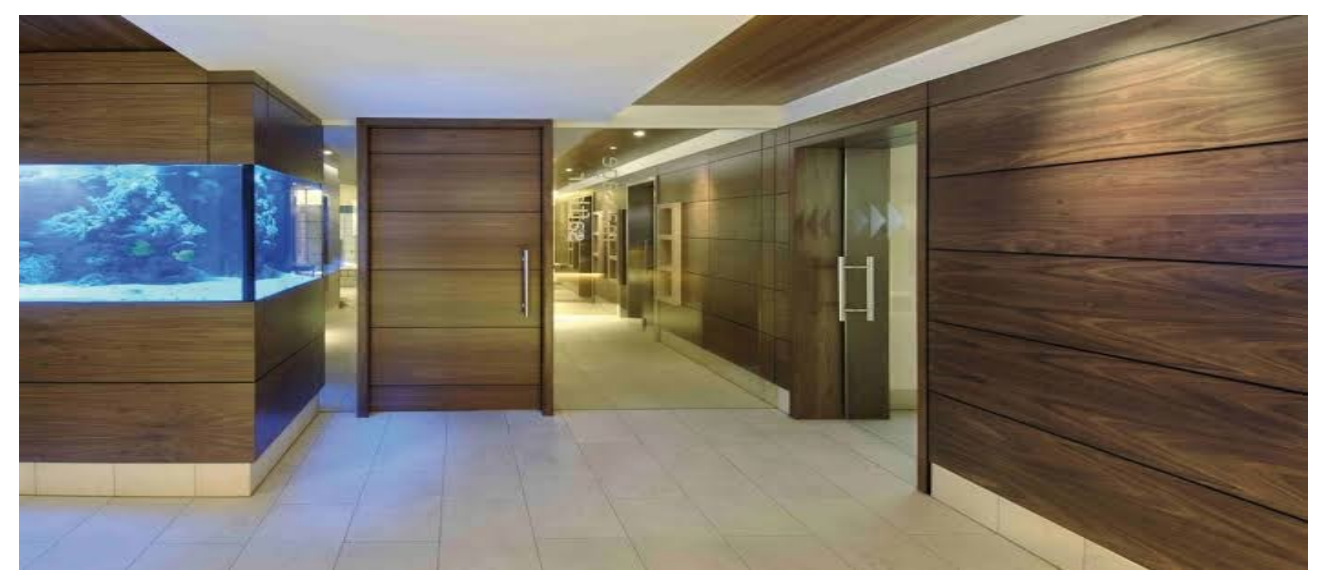

شكل رقم (ז)

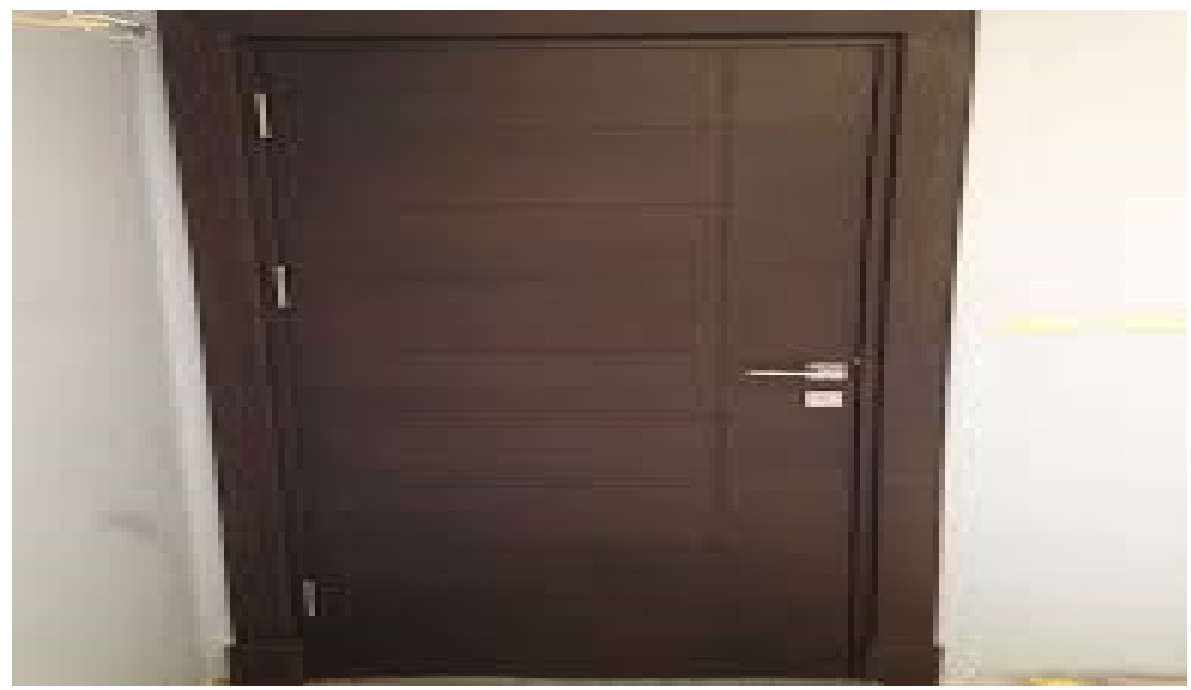

شكل رقم (广)

كما يمكن استخدامة فى تصميمات الاثاث المختلفة حيث انه يستخدم فى صناعة المكاتب

$$
\text { والطاولات (شكل رقم ) - (ن) }
$$



العدد الثالث عشر / المجلد الأول

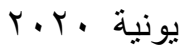
المجلة العلمية بحوث في العلوم و الفنون النوعيه
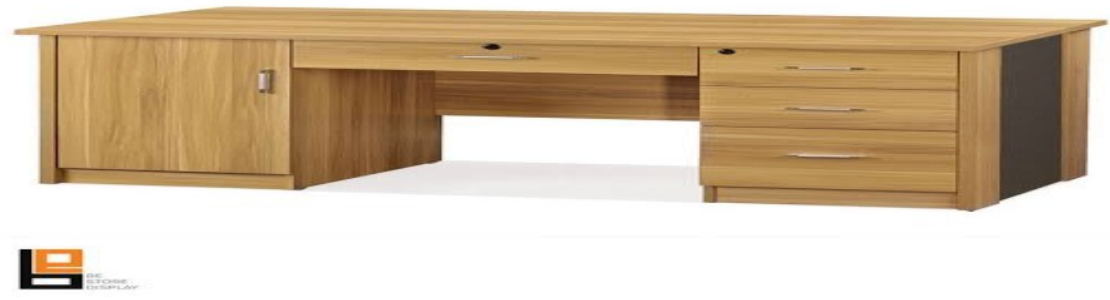

شكل رقم (ई)

\section{فى تصميم الارضياتHDF/ستخدام الألواح الخشبية}

فى التصميمات الداخلية بكثرة وذلك نظرا لخواصها

بأسم

المتميزة التى تتيح للمصمم الداخلى تتفيذ أفكارة التصميمية الى جانب قله تكلفتها المادية ويكثر استخدام هذة الالواح فى تصميم وتتفيذ الارضيات الخشبيه .(شكل رقم 0 )و (شكل رقم

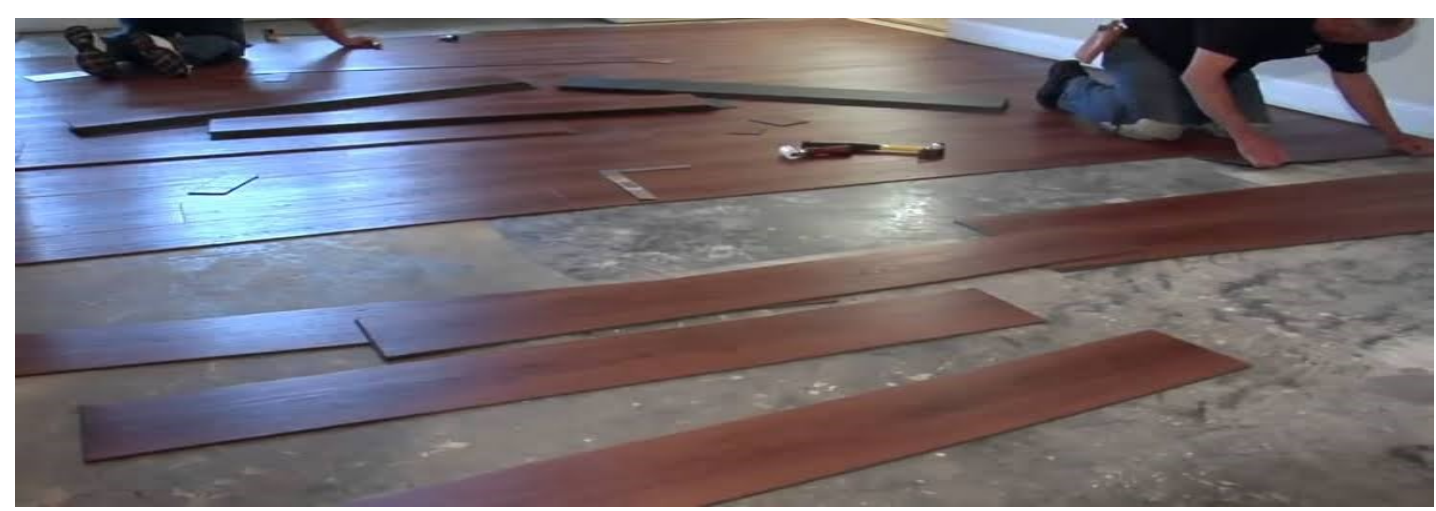

شكل رقم (0) 


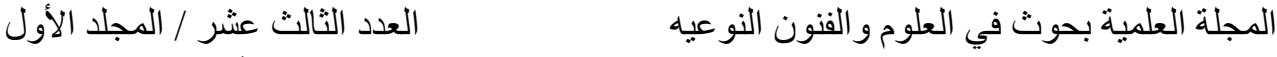

$$
\begin{aligned}
& \text { r. r. بونية }
\end{aligned}
$$

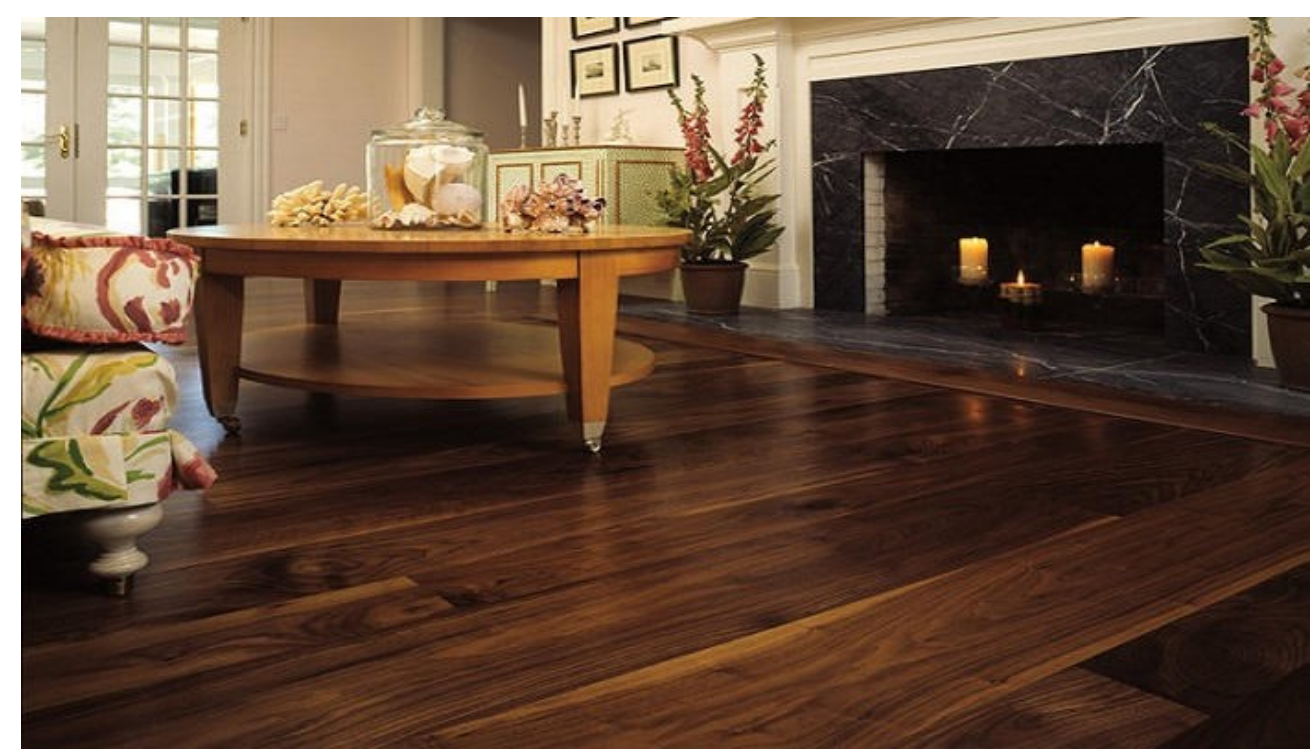

شكل رقم (؟)

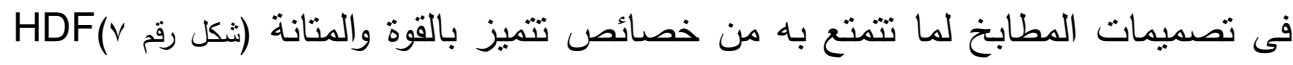

كما تستخدم الواح

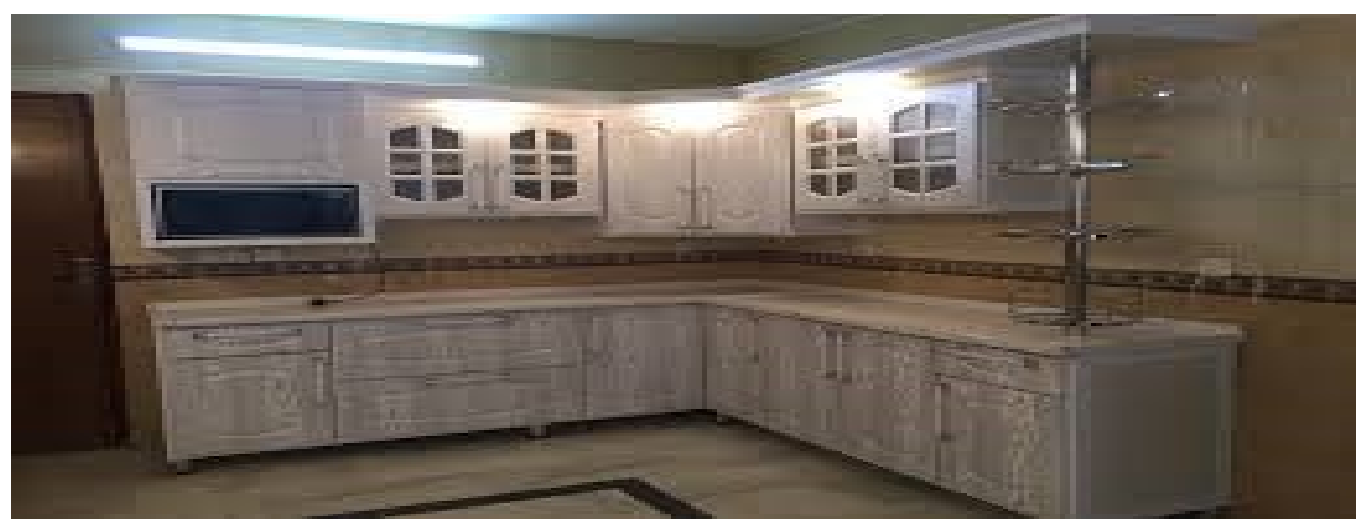

شكل رقم (v)

$1-$ https://almalnews.com

2- https://dubarter.com. 


\section{تطبيقات على الواح الخشب البلاستيك فى التصميمات :}

لقد ذكرنا من خلال هذة الدراسه مفهوم الخشب البلاستيك وطرق تصنيعة ويستخدم الخشب البلاستيك من قبل الدصم الداخلى فى تتفيذ أفكارة التصميمية وخاصة فيما يخص الارضيات والحوائط لما لهذة الالواح من خصائص متميزة من حيث قوتها ومقاومتها للرطوبة والتغيرات

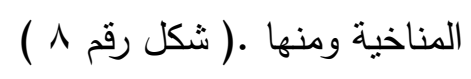

و(شكل رقم 9)(1) - 20)

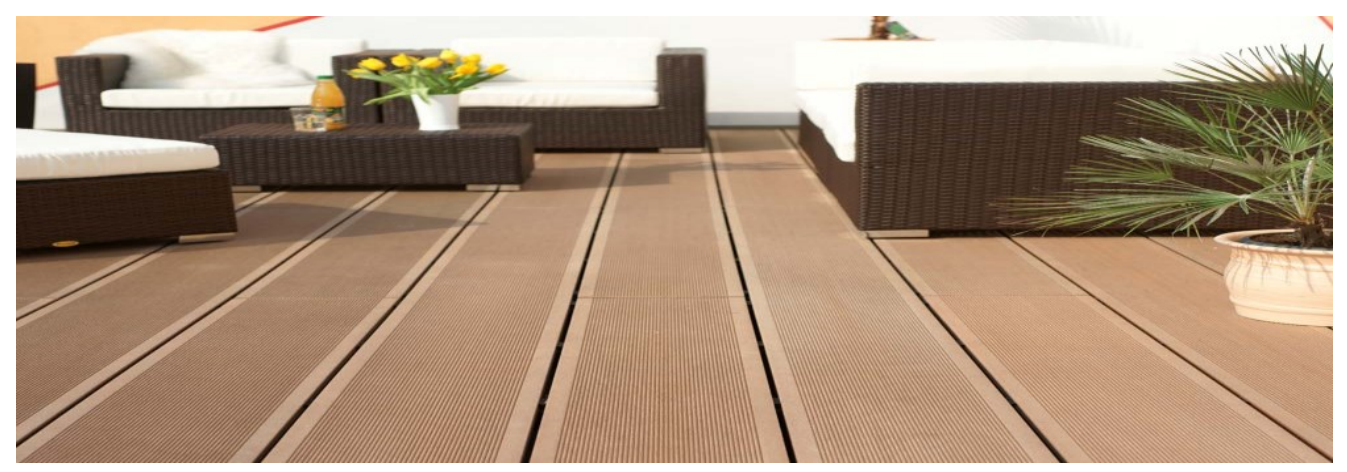

$$
\text { ارضيات من الخشب البلاستيك (شكل رقم } 1 \text { ) }
$$

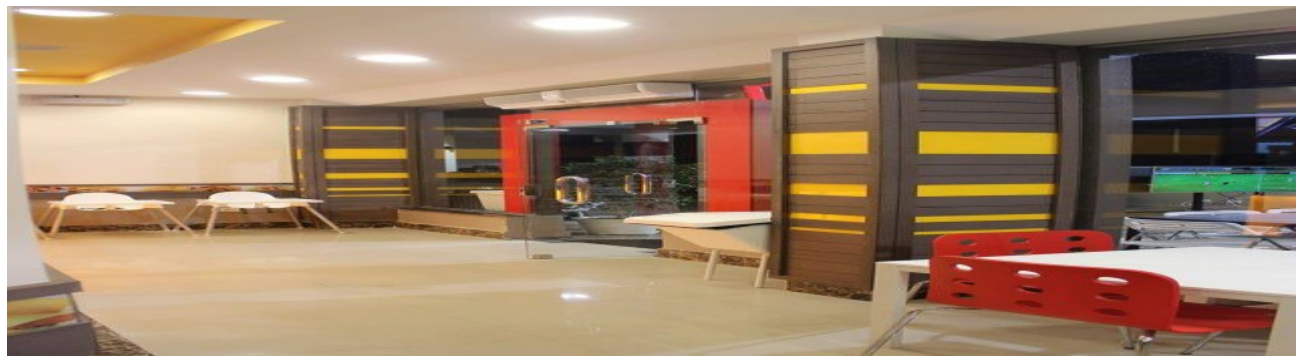

اعمدة تم تكسيتها بالواح الخشب البلاستيك (شكل رقم 9 
لقد نم التوصل من خلال هذه الدراسة الى العديد من النتائج وهى 1- الدور الكبير والفعال والأهمية الكبرى للاخشاب المصنعة من مواد صديقة للبيئة واستخداماتها المتعددة فى مجال التصميمات سواء كانت هذة التصميمات للفراغات الداخلية أو تصميمات خاصة بصناعة الاثاثات المختلقة . r- ان الأخشاب المصنعة من مواد صديقة للبيئة هى المستقبل الأمتل للمصمم المعمارى والداخلى لتتفيذ تصميماتة المختلفة لما لهذة الأخشاب من صفات فيزيائية اكتسبتها نتيجة استخدام التكنولوجيا المتقدمة والحديثة فى تصنيعها الامر الذى اتاح للمصصم تتفيذ افكار مبتكرة كان من الممكن ان بصعب علية نتفيذها بأستخدام الأخشاب الطبيعية أو المواد الخام

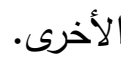

r- التوفير الأقتصادى فى تتفيذ التصميم الداخلى للفراغات او تصميم الاثاثات نظرا لقلة التكلفة الاقتصادية التى تستلزم تصنيع هذة الالواح الخشبية المصنعة مما كان له اثر كبير فى القضاء على احدى المعوقات التى كانت نقابل المصدم عند قيامة بتتفيذ فكرته التصميمية. ع- اتاحت صناعة الواح الاخشاب من خامات ومواد صديقة للبيئة الفرصة للتخلص من المخلفات الزراعية ومخلفات المصانع والتى كانت تؤثر بالسلب على البيئة المحيطه وذلك عن طريق الاستفادة من هذه المخلفات فى اعادة تدوبرها بطريقة علمية وتكنولوجية مبتكرة فى كى انتاج الواح خشبية يتم الاستفادة بها فى شتى المجالات وخاصة مجال التصميم. 0- ان الالواح الخثبية المصنعة وخاصة عند دمجها مع خامات اخرى ومعالجنها كيميائيا اكسبتها خواص جديدة غير منوفرة فى الاخشاب الطبيعية مثل مقاومة الحشرات والرطوبة 
والحرارة والحريق ومعظم الظروف المناخية الاخرى مما جعل هناك احتياج الى استخدامها للاستفادة من هذة الخصائص الجديدة.

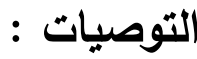

1- العمل على اجراء المزيد من الدراسات والابحاث حول اهمية وفاعلية استخدام الالواح الخشبية المصنعة من مواد وخامات صديقة للبيئه فى الانشاءات والتصميمات الداخلية للفراغات وفى تصميم الاثاثات المختلفة للعمل على الاستفادة القصوى من اى دراسة او بحث

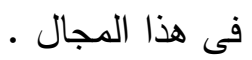
r- اقامة محاضرات وندوات للمصممين الحاليين لتوضيح مدى اهمية استخدام الالواح الخشبية المصنعة من خامات صديقة للبيئة فى مجالات التصميم المختلفة مع التعرف على احدث الطرق والاساليب التكنولوجية الحديثة فى تصنيع وانتاج هذه الالواح لتلافى اى سلبيات يمكن ايجادها فى هذة الالواح الخشبية من شأنها ان تعيق عملية التصميم • r- توضيح مدى اهمية الدور الذى تلعبة عملية انتاج وتصنيع الالواح الخشبية فى الحفاظ على البيئة المحيطة حيث انها نقوم على اعادة تدوير المخلفات المختلفة سواء مخلفات زراعية أو مخلفات مصانع او حتى مخلفات اخشاب قديمه ومتهالكة والاستفادة منها فى انتاج مواد جديدة تستخدم فى انتاج وتصميم الاثاثات المختلفة وتتفيذ عمليات التصميم قى الفراغات الداخلية للمبانى والانشاءات المعمارية الى جانب استخدامها فى مجالات اخرى بخلاف التصميمات مثل انتاج صناديق للمعدات او استخدامها فى انشاء الكبارى والمنشأت الخشبية المختلفة والى جانب ذلك التكلفة الاقتصادية المنخفضة لانتاج وتصنيع هذه الالواح الخشبية. ع- العمل على الإستفادة من مادة الخشب الصناعى و تطويرها التكنولوجى فى مجال التصميمات سواع التصميمات الداخلية أو تصميم الاثاثات التى تلائم العصر الحديث. 


\section{المراجع العربية :}

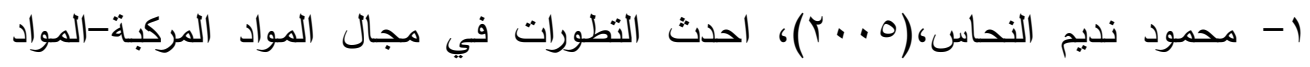
المركبة الصديقة للبيئة والقابلة لأعادة الاستخدام ،مجلة جامعة الملك عبد العزيز، المجلد السادس عشر ، العدد الأول، المملكة العربية السعودية .

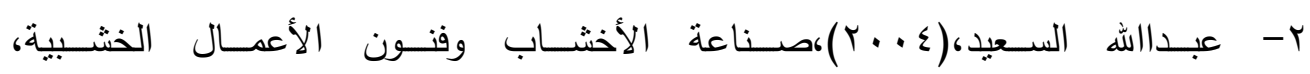
دارالبشير، عمان، الاردن. - مان.

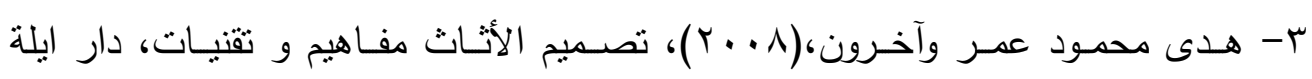
للنشر والتوزيع ،الطبعـة الأولى، عمان، الاردن. ع- تاج الدين حسين نصرون، (0. . ب)، خصائص وتقانة الأخشاب، دار عالم الكتب، الرياض.

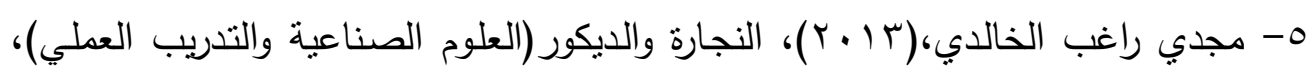
المستوى، الثالث، وزارة التربيه والتعليم،الاردن

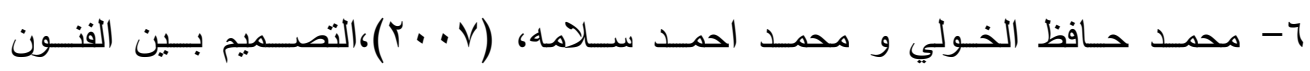
التشــكيلية والزخرفية،، مكتبة نانسي الطبعة الأولى، دمياط. V- محمد السيد سيد احمد ،(1) ب (1)، تكنولوجيا التصميم الداخلى والأثاث ، دار الزعيم لمنشر والتوزيع ، القاهرة.

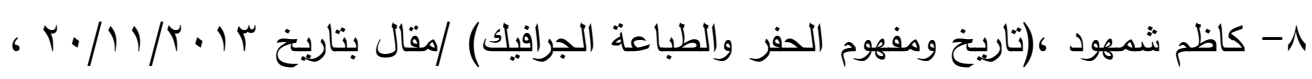
مركز الرافدين للبحوث الإستراتيحية. 


\section{المراجع الأجنبية :}

9- Fruehwald, A., Thoemen, H. (2008)' The rise of wood based panels. Presentation during the 3rd International Wood Academy, University of Hamburg. 10- NPA. 1993. Particleboard, ANSI A208.1-1993. Gaithersburg, MD: National Particleboard Association. 11-. BS EN 634-2:2007 Cement-bonded particleboards. Specifications. Requirements for OPC bonded particleboards for use in dry, humid and .external conditions, BSI 12- BS EN 622-‘(:2009)’ Fibreboards. Specifications. Requirements for dry process boards. 13- NP'(. 1994). Medium density fiberboard (MDF), ANSI A208.21994. Gaithersburg, MD: National Particleboard Association. 14- Maloney, T.M. 1993. Modern particleboard and dry-process fiberboard manufacturing. San Francisco, CA: Miller Freeman Publications.

15-(Davidová, Marie'(2016)' Wood as a primary medium to architectural performance : a case study in performance oriented architecture approached throught systems oriented design.

$$
\text { المواقع الأكترونية : }
$$

16- https://arab.dailyforex.com.

17- https://muslims-res.com.

18- .http://www.arab-ency.com.

19- https://theconstructor.org.

20- https://europlywood.com/

21 - http://singcore.com/education/faq.

22- http://www.woodplasticcompositepanel.com

.23- http://worldarab.mam9.com

24- https://ar.decoratex.biz.

25- https://www.utradeksa.com.

26- https://almalnews.com

27- https://dubarter.com.

28- https://aldecoregypt.com/w 
العدد الثالث عشر / المجلد الأول المجلة العلمية بحوث في العلوم و الفنون النوعيه

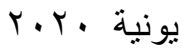

